\title{
Value of floral diversity of the Sanjay Gandhi National Park (SGNP)
} Ambika Joshi $^{*}$, Anudnya Kalgutkar ${ }^{1}$, Nitesh Joshi ${ }^{2}$

1Department of Botany, Jai Hind College, “A” Road, Churchgate, Mumbai 400 020, Maharashtra, India. ${ }^{2}$ Department of Botany, Rizvi College of Arts, Science and Commerce, Bandra (W), Mumbai - 400050, Maharashtra, India.

Received: December 22, 2015; Revised: January 12, 2016; Accepted: January 21, 2016.

\begin{abstract}
SGNP embraces floral species possessing medicinal, food and commercial values. Owing to over-collection, they have been listed as either being endemic, rare or endangered in Red Data Book. For complete representation of floristic components, seasonal floristic surveys were conducted every fortnight and to understand their value as medicine, food and commercial, information was gained from the local communities and resources from Nature Information Center of the SGNP. The survey identified 84 tree species from 28 families, 17 species of Shrubs from 8 families, 37 species of Herbs from 19 families, 20 species of Climbers from 11 families, 3 species of Bamboos from 1 family, 1 species each of Epiphyte and Parasite and 4 species of Palms. Of 84 species of trees, 81 were known to have an intrinsic value as food, commercial, medicinal, religious or all. 66 of 79 species of plants recorded showed a high inherent value and used by local communities to generate natural income. Having known of the values of trees, 6 of the 84 species of trees were recorded as endangered, vulnerable, rare or endemic to the region. Similarly, atleast 6 species of wild plants belonged to one of the categories of the Red Data List. It is quite evident that the species of plants in SGNP provide mankind with large number of goods and services. Recognizing their exquisite properties as medicinal, commercial and food, the forests can be considered as a source worth millions to enhance human wellbeing.
\end{abstract}

Key words: Biodiversity, human wellbeing, inherent and economical value, local communities, natural income, Red Data List

\section{Introduction}

The Sanjay Gandhi National Park (SGNP), home to several species of flora, spans around $104 \mathrm{~km}^{2}$ and is an example of one of the least represented biographic zones - the Malabar Coast of the Western Ghats which forms only $0.4 \%$ of the Protected Area network. Studies in the field of identification of floral species at the SGNP started as early as 1839 , where the first major work was done by John Graham and later published in 'A Catalogue of Bombay Plants' (1839). For the first time in 2002, the Botanical Survey of India (BSI) published records of the flora of Sanjay Gandhi National Park. The BSI accounts 151 Angiospermic families, 581 genera, 1078 species and 31 infraspecific taxa from the park. Some of the dominant families are Poaceae, Fabaceae, Cyperaceae and Acanthaceae (Pradhan SG., 2005).

Observations done through floristic survey of the park, shows that the park embraces species of flora that are either endemic, rare or endangered as recorded under the Red Data Book of Plants. Chlorophytum borivilianum is a rare herb recorded from the park and is listed as endemic to the National Park. The herb is also reported to now be endangered and vulnerable due to over collection as has been discussed in further part of this chapter. Dipcadi saxorum listed as vulnerable in the Red Data Book of Plants is also recorded from the park. Ceropegia vincifolia, an annual climber, found in the park, is also reported to have attained the status of being endangered due to over collection (Kehimkar I., 2000). The identification encompassing variations in seasons and through

\section{Corresponding Author}

Dr. A. Joshi,

Department of Botany,

Jai Hind College,

Mumbai, Maharshtra, India. diverse habitats, i.e. disturbed and undisturbed, gives an insight about the species that have been classified under various categories of the IUCN Red Data Book. This paper also appreciates the values, both as goods and services, of the flora and their contribution towards the society at large.

\section{Materials and Methods}

The study was aimed to monitor and record changes occurring in sites selected as disturbed and undisturbed in different seasons. Frequent visits to the study area and documenting species were primary methods in studying the flora of the park. For the purpose of collecting adequate data, so as to get a complete representation of the floristic components of the park, field trips were conducted every fortnight in all the seasons. Observations of changing biota were made during monsoon i.e. June to August, post monsoon i.e. October to November and during winter i.e. January to March. To examine these seasonal variations in biotic diversity of the park, flora and fauna encountered during different seasonal time frames were recorded and identified with aid of the Bombay Natural History Society (BNHS), Agharkar Research Institute (Pune) and Blatter Herbaria. References were also taken from Flora of Maharashtra (Almeida M.R., 2001 - 2009) and from The Flora of the Presidency of Bombay (Cooke T., 1901 - 1908). To have a complete understanding of the species and their value as medicine, food and commercial, locals of the SGNP were contacted while also using literature from Common Indian Wild Flowers (Kehimkar I., 
2000), A Celebration of Indian Trees (Kothari A.S., 2007) reports from FAO (Food and Agriculture Organization) and research articles published in The Hindu (2007 - 2013).

\section{Results}

The floristic survey at disturbed and undisturbed areas of the park categorized 84 different species of trees belonging to 28 families. Similarly, 17 species of Shrubs belonging 8 families, 37 species of Herbs belonging to 19 families, 20 species of Climbers belonging to 11 families, 3 species of Bamboos from one family, 1 species of Epiphyte and 1 species of Parasite and 4 species from one family of Palms have also been recorded from the park.

\section{Floristic Diversity of SGNP}

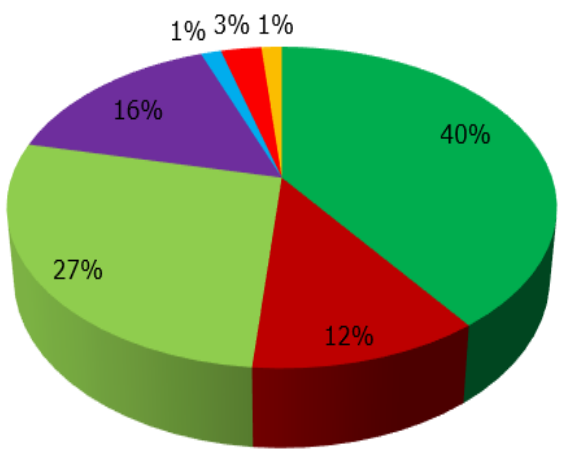

-Trees
-Shrubs
- Herbs
- Climbers
- Bamboos
- Epiphytes \& Parasites
- Palms

Figure 1: Flora Recorded by SGNPDifferentiation by Family

Floristic Diversity of SGNP - Differentiation by Family and Species

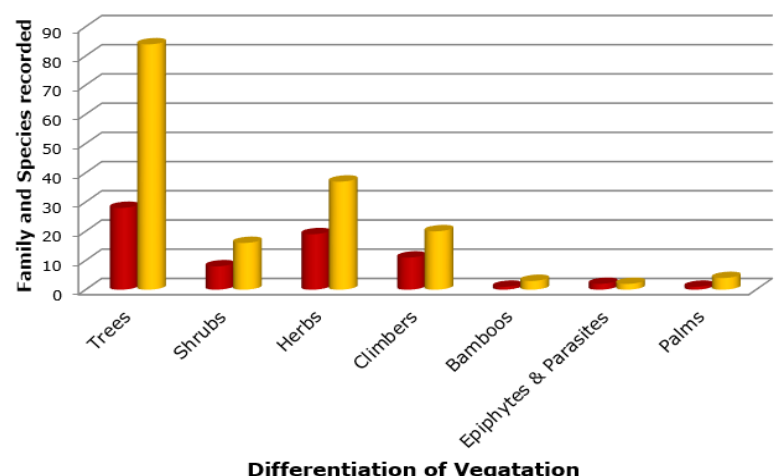

- Family - Species

Figure 2: Flora Recorded at SGNP Differentiation by Family and Species

\section{Value of Floral Diversity}

Observations made from the recordings of trees show that from 84 species belonging to 28 families, atleast 81 of them are known to have an intrinsic value as either as food, commercial, medicinal, religious or all values. From the trees recorded, flowers of Nyctanthes arbor - tristis and Mammea suriga are known to be used as religious offerings. Cochlospermum religiosum, Michelia champaca and Mitragyna parvifolia are also known to have religious importance alongside possessing commercial value while Ixora brachiata and Aegle marmelos possess both religious and medicinal values. Having known of the values of these trees, 6 of the 84 species of trees recorded are known to be endangered, vulnerable, rare or endemic to the region. While Garcinia indica and Atalantia racemosa are known to be endemic to the region, Flacourtia montana and Sysygium cumini are endangered and rare. Also, Ixora brachiat is known to be endangered and Miliusa tomentosa is regarded as a species being endemic, endangered and vulnerable. A graphical representation as given in Figure 3 gives percent distribution of the trees recorded in SGNP as food, commercial or medicinal source.

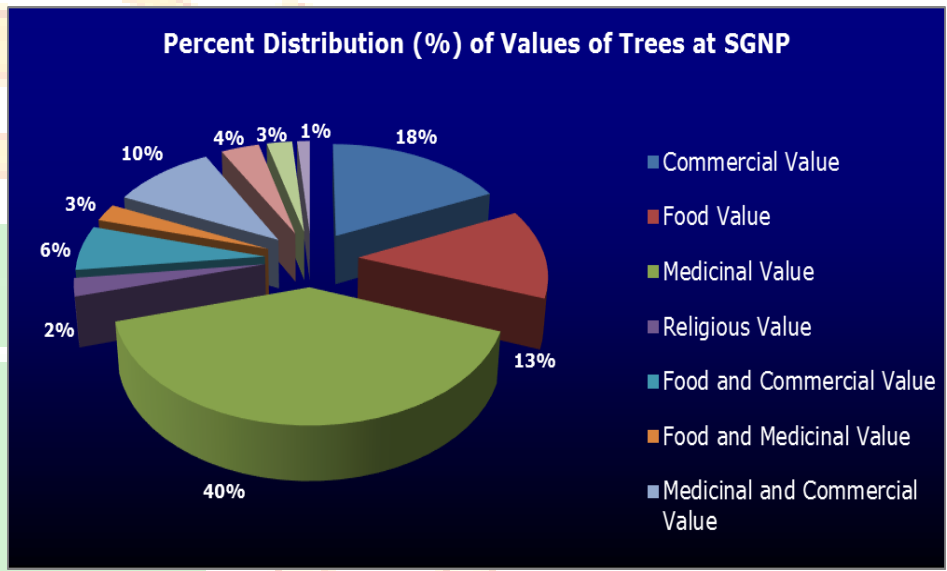

Figure 3: Distribution of trees that are used as food and have commercial and medicinal values

Of the total recorded species of trees, 40 percent possess medicinal value. Miliusa tomentosa, an endemic, endangered and vulnerable species found in the region of the park is known to have antibacterial properties while Terminalia chebula is known to have properties to cure blindness and inhibit the growth of malignant tumours. Baubinia racemosa is used as a traditional medicine in the treatment of diabetes. Syzygium cumini listed as endangered and rare is known for its medicinal properties to cure tooth and gum disorders, diabetes, diarrhea and ringworm due to its antibacterial properties.

Also, 13 percent of the trees are known to be economically important while serving as food source with high monetary returns. Two species of trees belonging to Family Anacardiaceae, viz; Anacardium occidentale and Mangifera indica, known throughout the country for their highly priced fruits are found in the park. Similarly, Annona reticulate and Annona squamosa, are also known for their highly priced fruit. In addition to value as food, Annona squamosa is considered to have medicinal properties where bark, leaves and roots are used in traditional medicines. The fruits of Tamarindus indica are used as a flavoring agent in 
Indian cuisines. Some trees though do not support high commercial value for their produce as food, the fruits and other parts of these trees are used by locals as food, thus supporting and sufficing their victuals; for example, the fruits, young pods and leaves of Sesbania grandiflora are eaten as vegetables in Southeast Asia.

SGNP has recorded species of trees comprising 18 percent of their value to produce commercial goods from the sum total of economically important values, which not only generate high quality timber but also commercially viable non timber products. Tectona grandis, Acacia chundra, Acacia catechu and Mitragyna parvifolia found in the park are known for their highly valued and durable timber used for construction of buildings, boats and furniture. Pterospermum canescens, Manilkara hexandra, Gardenia latifolia, Peltophorum pterocarpum, Diospyros melanoxylon are other species seen in the park which are valued for their hard wood. Samanea saman is a species that has value as both fuel wood and timber. The wood of Wrightia tinctoria is extensively used for turnery. The wood of Terminalia elliptica is used for furniture, cabinetwork, joinery, paneling, boat - building, railroad cross - ties and decorative veneers while Macaranga peltata and Melia dubia are highly used in plywood industry. Apart from the trees known to produce commercial timber and fuel wood, species like Bombax ceiba and Cochlospermum religiosum are known for the cotton obtained from their fruit, used for filling economically priced pillows, quilts, sofas etc. Parts of Butea monosperma are used for timber, resin, fodder, medicine, and dye. Of all the wild plants studied, most of all showed high fundamental and commercial value.

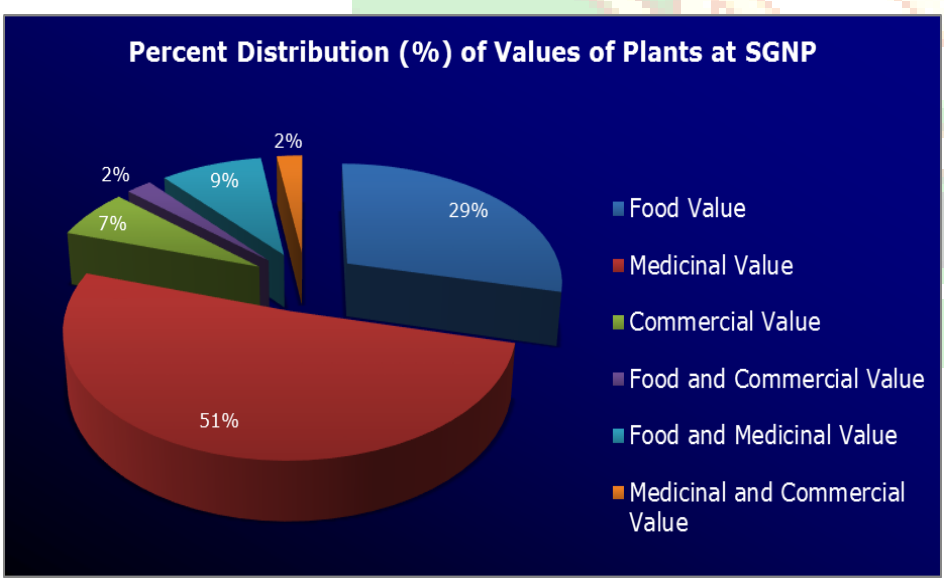

Figure 5.4: Distribution of plants (shrubs, herbs, climbers, grasses) that are used as food and have commercial and medicinal values

51 percent comprise of plants that possess medical properties and are used as traditional / folk medicines, for example, Rauwolfia serpentine has been used in traditional medicines to cure hypertension and high blood pressure. The roots of the plants contain alkaloids that are useful in curing these diseases. However, over - collection of the plant has endangered the plant in the wild. Chlorophytum borivilianumi, a plant endemic to the SGNP also holds a high market value due it medicinal properties. Its over - collection to develop drugs has resulted in the plant being endangered from the wild.

From the plant species identified, 29 percent of them were known to have been used as food by natives or sold in markets. Parts of the plants like tubers (Curcuma pseudomontana), leaves (Hygrophila serphyllum), and fruits (Capparis zeylanica) are used by local communities. However, the over - collection of these products from the forests have resulted in the species becoming endangered. Ceropegia vincifolia, a twiner, produces tubers that are cooked and eaten like potatoe. Extensive collection of tubers for food by tribal communities has endangered this plant. Similarly, over - collection of tubers of Gloriosa superba for alkaloid extraction has endangered this plant in the wild. Flower stalks of Amorphophallus commutatus are sold by tribals as a monsoon produce. These flower stalks yield a high cost in local markets which has resulted in the decrease of its produce due to over - exploitation.

The two species of bamboo, namely, Bambusa arundinacea and Dendrocalamus strictus, have high commercial value as building materials. Urena lobata is cultivated for termite - and - water resistant fibre used in making fishing line, rope and binding cord. The plant is seen growing gregariously in the Park.

\section{Conclusion}

From the discussion made herewith, it is quite evident that the SGNP like all forests is home to several species of plants that provide mankind with large number of goods and services. Recognizing their exquisite properties as medicinal, commercial and food, the forests can be considered as a source worth millions. Thus, the foremost pressure on such habitats comes in form of high levels of demand for their goods (raw materials). Such high demand sets in an interlocking loop affecting the overall survival of the species which begins with the high demand triggering high volume extraction coupled with destructive methods of harvesting which invariably damage the population, subsequently affecting the natural regeneration of these species leading to altered availability of the goods and services. It thus becomes imperative as a social responsibility for conserving and protecting the fragile ecosystem from such practices of over and unsustainable harvesting. This has reinforced the urgent need to conserve the resource base in forests; however, the challenge is to assign the conservation priorities, given the gap in our 
current understanding in respect of natural distribution and population size, causes and kinds of threats, issues related to regeneration, reproductive biology and phenology, critical socio - economic elements operating in a habitat, prevailing harvesting mechanisms and other trade - related pressures, propagation methods and management priorities for augmenting the resource base.

\section{References}

1. Almeida MR \& Chaturvedi N, Flora of Maharashtra, Blatter Herbarium, 1996.

2. Almeida MR, Flora of Maharashtra IIIA - VA, Orient Press, Mumbai, 2001 - 2009.

3. Almeida MR, Flora of Maharashtra, Bombay Natural History Society, 2009.

4. Cooke T, The Flora of the Presidency of Bombay, Volume I and II, Published under the Authority of the Secretary of State for India in Council, 1901 1908.
5. FAO, The status of forests: The Global Forest Resources Assessment 2000, Key Issues in the Forest Sector Today, Part II, 2000.

6. Kehimkar I, Common Indian Wild Flowers, Mumbai: Bombay Natural History Society, 2000.

7. Kothari A, A Celebration of Indian Trees, Mumbai: National Society of the friends of the Trees in association with Marg Publications, 2007.

8. Kothari A \& Pathak N, Communities in conservation - Traditions to the rescue, The Hindu: Survey of the Environment, 2009, 77 - 79, $81-88$.

9. Pradhan SG, The Flora of Sanjay Gandhi national park, Borivali, Mumbai, Botanical Survey of India, Calcutta, 2005.

\section{Cite this article as:}

Ambika Joshi, Anudnya Kalgutkar, Nitesh Joshi. Value of floral diversity of the Sanjay Gandhi National Park (SGNP). Annals of Plant Sciences 5.2 (2016): 1276-1279.

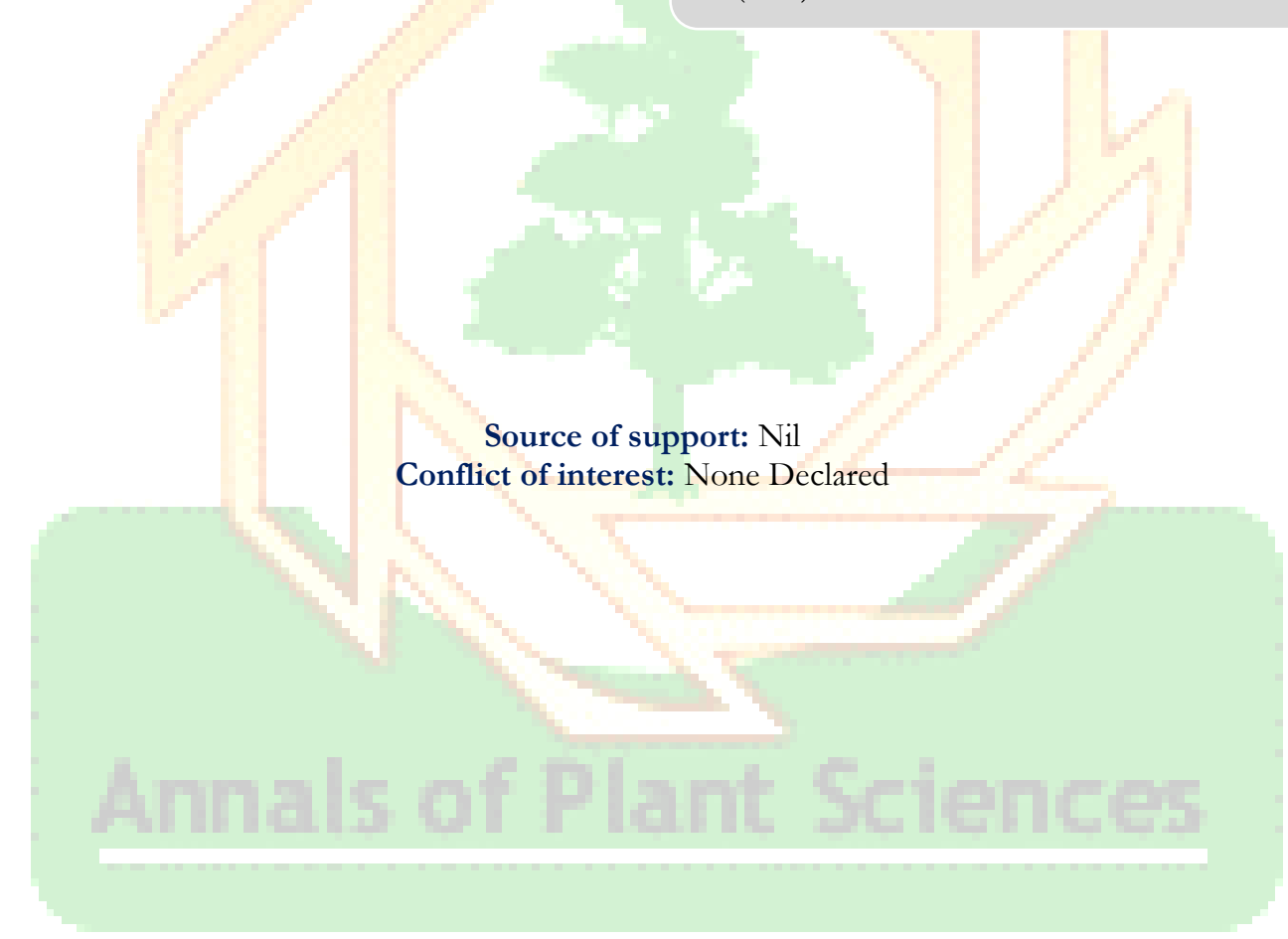

